\title{
Analysis And Modelling Of Geoelectric Data Modeling For The Identification Of Groundwater aquifer At Cisarua Area, West Bandung
}

\author{
Analisis Dan Pemodelan Data Geolistrik Untuk Identifikasi Akuifer Airtanah Di Daerah Cisarua, \\ Bandung Barat
}

\author{
Daniswara, A. ${ }^{1 *}$, Dahrin, D. ${ }^{2}$, dan Setianingsih ${ }^{2}$ \\ ${ }^{1}$ Program Studi Teknik Geofisika, Fakultas Teknik Pertambangan dan Perminyakan, Institut Teknologi Bandung, \\ Jalan Ganesa 10 Bandung, 40132 \\ ${ }^{2}$ Kelompok Geofisika Terapan dan Eksplorasi, Fakultas Teknik Pertambangan dan Perminyakan, \\ Institut Teknologi Bandung, Jalan Ganesa 10 Bandung, 40132 \\ *Email: ardhitodaniswara@gmail.com
}

Submit: 10 Juni 2019; Revised: 22 Juli 2019; Accepted: 26 Agustus 2019

\begin{abstract}
Groundwater is the main need of society in everyday life. Groundwater is one of renewable resources but it doesnt mean that it can be exploitated without limit. Several factors that affect the availability of groundwater derived from nature such as geological conditions, rainfall, and green areas should be considered. Water in the soil is stored in a porous layer and has a good permeability is called an aquifer. Cisarua area is located in West Bandung regency, West Java which is a hilly area that has a topography with a slope ranging from normal to steep. The land use in this area is still dominated with plantation and forest as green area. Groundwaer aquifer characteristics in that area needs to be examined and analysed for the needs of the community and agricultural business. In this research, the writer used inversion modeling technique of geoelectric data to visualize the condition of subsurface. Resistivity inversion modelling of apparent resistivity data as a result of resistivity method with Wenner-Schlumberger configuration is then carried out with least-square method. The initial model is modified in an iterative manner such that the sum of square error of the difference between the model response and the observed data values is minimized. The result of resistivity modelling is used for analysis of aquifer characteristic such as lithology, depth and structure along with considering geological reference. As the result of modelling, the area of measurement is divided into three zones which are Zone of aeration, Zone of Saturation, and endapan formasi. Zone of aeration is located at depth 0-25 $\mathrm{m}$ with resistivity 20-100 Ohm.m and the predicted lithology is gravel or weathered soil. Zone of Saturation (akuifer) is located at depth 25-60 $\mathrm{m}$ with resistivity 4-30 Ohm.m and the predicted lithology is sandstone or clay. Endapan Formasi Cibereum is located at more than $60 \mathrm{~m}$ from ground with resistivity more than 100 Ohm.m and the predicted lithology is sandy tuff or dry breccia.

Keywords:
\end{abstract}

\begin{abstract}
Abstrak: Airtanah merupakan kebutuhan utama masyarakat dalam kehidupan sehari-hari. Airtanah adalah salah satu sumber daya alam yang dapat diperbaharui, tetapi hal ini tidak berarti airtanah dapat dieksploitasi tanpa batas. Beberapa faktor yang mempengaruhi ketersediaan airtanah yang berasal dari alam seperti kondisi geologi, curah hujan, dan lahan hijau harus dipertimbangkan. Air yang terdapat di dalam tanah terkandung pada lapisan yang berpori dan memiliki permeabilitas yang baik disebut akuifer. Daerah Cisarua terletak di Kabupaten Bandung Barat, Jawa Barat merupakan daerah perbukitan yang memiliki topografi dengan lereng yang landai hingga curam. Tata guna lahan pada daerah ini masih didominasi area perkebunan atau hutan sebagai kawasan hijau. Identifikasi akuifer pada daerah tersebut perlu dilakukan penelitian untuk kebutuhan masyarakat dan bisnis agrikultur. Pada penelitian ini, penulis menggunakan teknik pemodelan inversi data geolistrik untuk mencitrakan kondisi bawah permukaan. Data hasil pengukuran geolistrik metode wenner-schlumberger berupa tahanan jenis semu kemudian dilakukan pemodelan inversi dengan metodeleast square inversion. Model awal dimodifikasi secara iteratif sehingga jumlah kesalahan kuadrat (sum of square error) dari perbedaan antara respons model (model response) dan nilai data yang diamati diminimalkan. Dari hasil pemodelan, daerah penelitian dapat dibagi menjadi tiga zona yaitu Zone of aeration, Zone of Saturation, dan endapan formasi. Keberadaan akuifer di daerah Cisarua berada di kedalaman dengan nilai resistivitas dengan membandingkan dengan data dan referensi geologi di daerah penelitian. Zone of aeration berada di kedalaman 0-25 m dari permukaan dengan rentang resistivitas 20-100 Ohm.m dan diduga litologinya berupa kerikil atau tanah hasil pelapukan. Zone of Saturation (akuifer) berada di kedalaman 25-60 m dari permukaan dengan rentang resistivitas 4-30 Ohm.m dan
\end{abstract}


diduga litologinya berupa lempung atau pasir. Endapan Formasi Cibereum berada di kedalaman lebih dari $60 \mathrm{~m}$ dari permukaan dengan rentang resistivitas lebih dari 100 Ohm.m dan diduga litologinya berupa pasir tufaan atau breksi kering.

Kata kunci:

\section{PENDAHULUAN}

Airtanah menjadi kebutuhan penting dalam kehidupan masyarakat seperti untuk kebutuhan air minum, kebersihan rumah tangga, industri, dan pertanian. Seiring dengan pertumbuhan jumlah penduduk yang semakin tinggi, kebutuhan akan air yang bersih menjadi semakin besar. Airtanah merupakan salah satu komponen dalam peredaran air di bumi yang dikenal sebagai siklus hidrologi. Dengan demikian airtanah adalah salah satu sumberdaya alam yang dapat diperbaharui, tetapi hal ini tidak berarti sumberdaya ini dapat dieksploitasi tanpa batas. Eksploitasi airtanah yang tidak terkontrol dapat mengakibatkan dampak negatif terhadap keseimbangan alam itu sendiri.

Beberapa faktor yang mempengaruhi ketersediaan airtanah yang berasal dari alam seperti kondisi geologi, curah hujan, daerah resapan dan lahan hijau harus dipertimbangkan. Banyaknya air yang meresap ke tanah selain bergantung kepada ruang dan waktu, juga dipengaruhi kecuraman lereng dan kondisi material permukaan tanah. Airtanah berada di bawah permukaan tanah dalam zona jenuh (saturated zone) yang memiliki tekanan hidrostatis sama atau lebih besar dari tekanan atmosfer. Airtanah tersimpan dalam formasi geologi yang disebut akuifer berupa material atau batuan berpori dengan syarat dapat menyimpan air dan memiliki permeabilitas yang baik. Hal ini juga bergantung kepada kondisi cuaca dan curah hujan yang mempengaruhi jumlah resapan (recharge) dan jumlah air yang keluar (discharge). Jumlah ketersediaan lebih banyak dibanding penarikannya, tetapi air yang berada di dalam tanah tidak dapat seluruhnya diambil ke permukaan untuk digunakan karena perlunya juga cadangan air tetap dalam tanah untuk mempertahankan struktur tanah atau menghindari land subsidence. Daerah penelitian ini berada di Cisarua, Bandung Barat, berjarak sekitar $15 \mathrm{~km}$ utara Kota Bandung dan memiliki topografi yang landai hingga curam. Tata guna lahan pada daerah ini masih didominasi area perkebunan atau kawasan hutan sebagai kawasan hijau dan belum banyak mengalami perkembangan bangunan seperti kota-kota besar. Daerah ini diharapkan dapat menjadi sumber daerah resapan airtanah.

Berdasarkan pertimbangan di atas, penulis melakukan pemodelan data tahanan jenis untuk mengetahui kondisi di bawah permukaan dari hasil pengukuran metode geolistrik berkonfigurasi Wenner-Schlumberger pada area pengukuran di daerah Cisarua, Bandung Barat. Data diambil dari hasil pengukuran yang dilakukan pada tanggal 28 September 2017. Metode Geolistrik adalah metode geofisika aktif yang digunakan untuk mengetahui nilai tahanan jenis dari batuan di bawah permukaan dengan menginjeksikan arus listrik. Pengukuran dengan metode geolistrik menghasilkan nilai resistivitas semu sehingga diperlukan pemodelan lebih lanjut untuk menentukan batas-batas lapisan. Pemodelan dengan metodeleast square inversion bertujuan

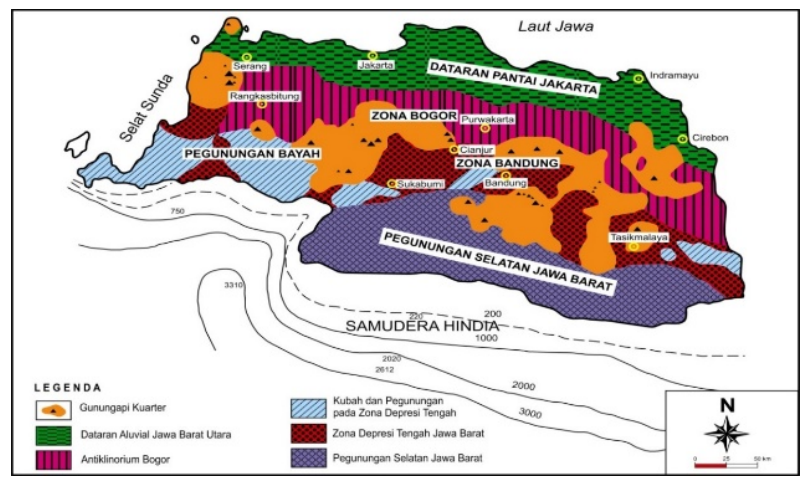

Gambar 1. Peta fisiografis Pulau Jawa (VanBemmelen, 1949).

untuk mendapatkan sebuah model dua dimensi yang memberikan respon yang mirip dengan nilai terukur sesungguhnya Loke (2004). Pemodelan dilakukan dengan perangkat lunak RES2DINV. Hasil dari pemodelan dari metode ini akan digunakan dalam analisis posisi kedalaman dan batas akuifer airtanah serta litologi di bawah permukaan dengan mempertimbangkan aspek geologi. Hasil analisis dari akuifer ini diharapkan dapat digunakan untuk intensifikasi eksplorasi sumber mata air di daerah tersebut.

\section{GEOLOGI REGIONAL}

Daerah Jawa Barat berdasarkan VanBemmelen (1949), secara fisiografis dan struktur yang memanjang dari arah timur ke barat dapat dibagi menjadi empat bagian yaitu Pegunungan Selatan Jawa Barat (The Southern Mountains of West Java), Zona Bandung (The Bandung Zone), Zona Bogor (The Bogor Zone), dan Dataran Rendah Batavia (The lowland plain of Batavia). Daerah penelitian masuk ke dalam Zona Bandung atau biasa disebut dengan Zona Depresi Tengah. Zona Bandung sebagian besar terisi oleh endapan vulkanik muda kuarter dan endapan alluvial (VanBemmelen, 1949).

Secara umum daerah Bandung bagian utara merupakan daerah dengan dataran tinggi dan perbukitan hasil dari proses erosi lereng vulkanik (eroded lower volcanic slope) (Dam, 1994). Berdasarkan klasifikasi VanZuidam (1983), daerah ini berada pada satuan perbukitan kaki gunung tangkuban parahu dengan ciri memiliki kontur yang cukup rapat. Kemiringan lereng berkisar antara agak landai hingga agak curam (2-16 derajat).

Menurut Martodjojo (2003), wilayah Jawa Barat dibagi menjadi tiga mandala sedimentasi yaitu Mandala Sedimentasi Banten, Mandala Sedimentasi Bogor dan Paparan Kontinen Utara. Daerah penelitian termasuk di dalam Mandala Sedimen Bogor terletak di selatan Mandala Paparan Kontinen Utara. Mandala sedimentasi ini dicirikan oleh endapan aliran gravitasi, yang kebanyakan berupa fragmen batuan beku dan batuan sedimen, seperti andesit, basalt, tuf, dan batugamping (Martodjojo, 2003). Menurut Koesoemadinata dan Hartoni (1981), Formasi Cibeureum berbentuk kipas yang bersumber dari Gunung Tangkuban parahu. Formasi ini terutama terdiri atas perulangan breksi dan tuf dengan tingkat konsolidasi rendah serta beberapa sisipan lava basal, dengan umur Plistosen Akhir Holosen. Breksi dalam for- 
masi ini adalah breksi vulkanik yang disusun oleh fragmenfragmen skoria batuan beku andesit basal dan batu apung. Sebaran formasi ini di permukaan adalah di bagian tengah. Litologinya terutama terdiri atas batulempung, batulanau, dan batupasir yang belum kompak dengan umur Holosen. Formasi ini mempunyai hubungan menjemari dengan Formasi Cibeureum bagian atas.

\section{DATA DAN PENGOLAHAN}

Daerah penelitian airtanah dengan metode tahanan jenis ini berada di Kecamatan Cisarua, Kabupaten Bandung Barat, Jawa barat. Letak geografis Kabupaten Bandung Barat terletak pada $107^{\circ} 22 \mathrm{BT}$ sampai $108^{\circ} 05 \mathrm{BT}$ dan $6^{\circ} 41 \mathrm{LS}$ sampai $7^{\circ} 19$ LS, sedangkan secara administratif Kabupaten Bandung Barat memiliki batas wilayah sebagai berikut: sebelah utara berbatasan dengan Kabupaten Purwakarta dan Kabupaten Subang, sebelah timur berbatasan dengan Kota Cimahi, Kota Bandung dan Kabupaten Bandung, sebelah selatan berbatasan dengan Kabupaten Bandung, dan sebelah barat berbatasan dengan Kabupaten Cianjur.

Pada daerah penelitian, dilakukan pengukuran metode tahanan jenis dengan konfigurasi schlumberger-wenner. Jumlah elektroda adalah 56 buah dan minimum jarak spasi antar elektroda adalah 10 meter. Terdapat 3 line pengukuran di lokasi yaitu PRP2, PRP3, dan PRP4. Pada penelitian ini, penulis melakukan pemodelan inversi data geolistrik dengan perangkat lunak RES2DINV . Proses inversi yang dilakukan adalah dengan menggunakan metodaleast square inversion, data diiterasi sampai mendapatkan nilai error yang terkecil agar didapatkan penampang bawah permukaan yang paling mendekati aslinya.

\section{HASIL DAN PEMBAHASAN}

Hasil pemodelan inversi dengan perangkat lunak RES2DINV menghasilkan profil penampang 2D secara vertikal yang menunjukan kedalaman dan sebaran resistivitas semu. Gambar 1-3 menggambarkan nilai resitivitas yang bervariasi pada pseudosection dan memberikan nilai RMS eror terkecil setelah dilakukan iterasi sebanyak 3 kali. Measured apparent resistivity pseudosection merupakan gambar dari hasil model data yang terukur di lapangan. Calculated apparent resistivity pseudosection merupakan model hasil dari perhitungan untuk mendekati model di lapangan.

Inverse model resistivity section merupakan hasil inversi dari model perhitungan. Nilai resistivitas yang rendah biasanya berhubungan dengan lapisan konduktivitas yang tinggi sehingga dapat menunjukkan keberaaan zona tersaturasi atau akuifer. Sedangkan nilai resistivitas yang tinggi berhubungan dengan lapisan dengan konduktivitas yang rendah sehingga dapat diasumsikan bahwa lapisan tersebut hanya sedikit mengandung air atau unsaturated zone. Pada penampang PRP 2, nilai resistivitas bawah permukaan berkisar antara 7-180 Ohm.m. Nilai resistivitas yang rendah ditunjukkan oleh warna biru muda hingga tua dengan nilai resistivitas berkisar antara 7-18 Ohm.m. Pada penampang PRP 3, nilai resistivitas berkisar antara 4-280 Ohm.m dan nilai resistivitas rendah berkisar antara 4-15 Ohm.m.

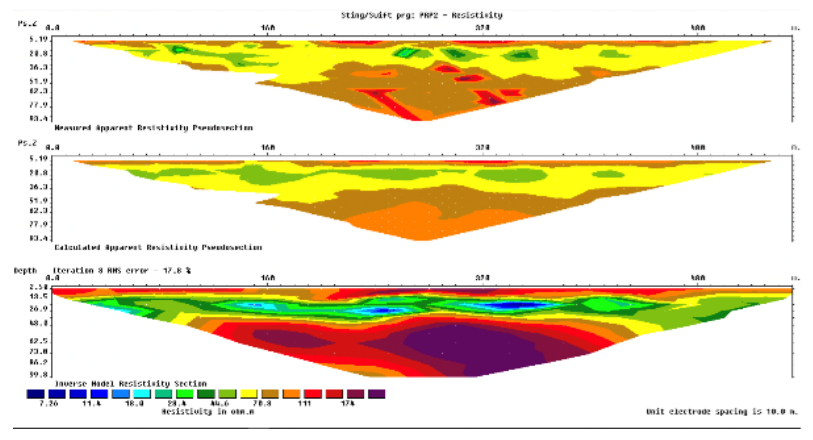

Gambar 2. Hasil pemodelan RES2DINV line PRP2.

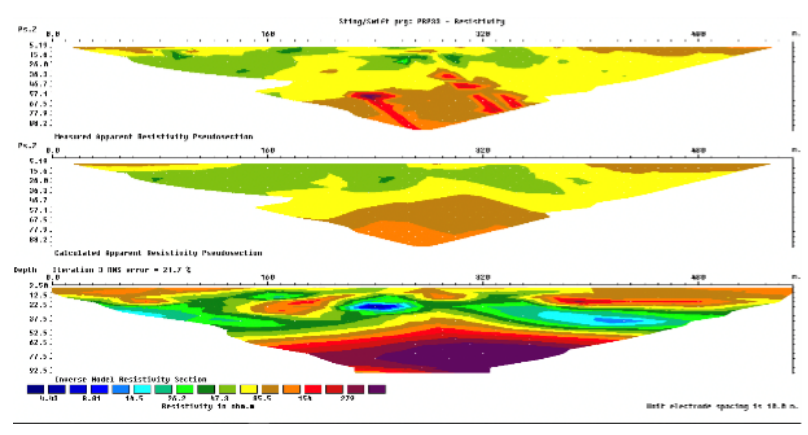

Gambar 3. Hasil pemodelan RES2DINV line PRP3.

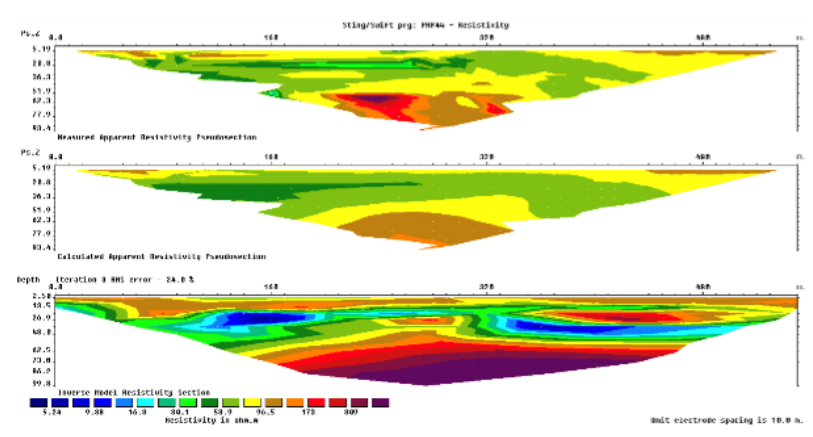

Gambar 4. Hasil pemodelan RES2DINV line PRP4.

Pada penampang PRP 4, nilai resistivitas berkisar antara 5-310 Ohm.m dan nilai resistivitas rendah berkisar antara 5-17 Ohm.m. Ketebalan akuifer bervariasi dari 10-20 m. Hal tersebut dapat mengindikasikan keberadaan saturated zone dan bagian paling atas dari zona tersebut merupakan muka air tanah (water table). Nilai resistivitas diatas 100 Ohm.meter dan ditunjukkan oleh warna oranye hingga ungu menunjukkan keberadaan unsaturated zone.

Berdasarkan distribusi vertikal Todd dan Mays (2005) hasil dari pemodelan inversi dapat diinterpretasi sebagai zone of aeration, water table, Zone of Saturation (aquifer) dan Formasi Endapan Cibereum sebagaimana ditunjukkan pada Gambar 5. Litologi aeration zone diasumsikan berupa kerikil atau tanah hasil pelapukan dengan rentang nilai resistivitas 20-100 $\Omega . m$ pada kedalaman 0-25 m. Pada Zone of Saturation atau aquifer berupa lempung atau pasir dengan rentang nilai resistivitas 4-30 $\Omega . \mathrm{m}$. di kedalaman 25-60 $\mathrm{m}$ dan unsaturated zone atau Formasi Endapan Cibereum 


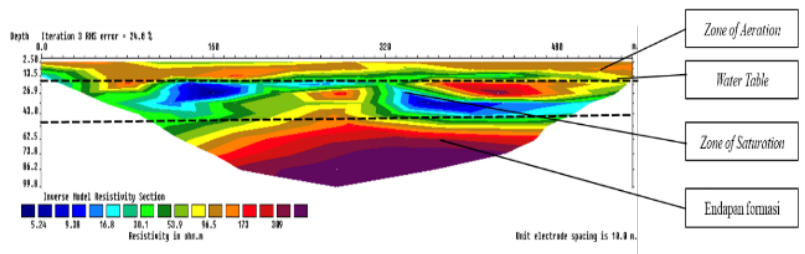

Gambar 5. Interpretasi hasil pemodelan PRP2 (1b), PRP3 (2b) dan PRP4 (3b).

berupa pasir tufaan dan breksi kering dengan nilai resistivitas $>100 \Omega . \mathrm{m}$ di kedalaman $>60 \mathrm{~m}$.

\section{KESIMPULAN}

Zona penelitian air tanah dapat diidentifikasi menjadi tiga zona yaitu Zone of aeration, Zone of Saturation, dan Endapan Formasi Cibereum. Zone of aeration berada di kedalaman $0-25 \mathrm{~m}$ dari permukaan dengan rentang resistivitas 20- $100 \mathrm{Ohm} . \mathrm{m}$ dan diduga litologinya berupa kerikil atau tanah hasil pelapukan. Zone of Saturation (akuifer) berada di kedalaman 25-60 $\mathrm{m}$ dari permukaan dengan rentang resistivitas 4-30 Ohm.m dan diduga litologinya berupa lempung atau pasir. Endapan Formasi Cibereum berada di kedalaman lebih dari $60 \mathrm{~m}$ dari permukaan dengan rentang resistivitas lebih dari 100 Ohm.m dan diduga litologinya berupa pasir tufaan dan breksi kering. Zona akuifer dapat berfungsi sebagai tempat penyimpanan cadangan air bersih pada periode hujan dan kemarau karena berada di tempat yang lebih tinggi dibandingkan dengan daerah sekitarnya.

\section{DAFTAR PUSTAKA}

Van Bemmelen, R.W. (1949). The geology of Indonesia, Martinus Nyhoff, The Haque, Nederland.

Loke, M.H. (2004). Tutorial 2D and 3D electrical imaging surveys. Penang, Geotomo Software.

Dam, M.A.C. (1994). The Late Quaternary Evolution of the Bandung Basin, West- Java, Indonesia, Thesis Vrije Universiteit, Amsterdam, 252 halaman.

Van Zuidam. (1983). Guide to Geomorphologic- Aerial Photographic Interpretation and Mapping, International Institute for Geo- Information Science and Earth Observation, Enschede.

Martodjojo, S., (2003). Evolusi Cekungan Bogor, Jawa Barat, Disertasi S3, Fak. Pasca Sarjana, Penerbit ITB, Bandung, 238 halaman.

Koesoemadinata, R.P . dan Hartono, D. (1981). Stratigrafi dan Sedimentasi Daerah Bandung. Proceedings PIT X Ikatan Ahli Geologi Indonesia, Bandung.

Todd, D. K. dan Mays, L. W. (2005). Groundwater Hydrology, John Wiley \& Sons, New Jersey, 636 halaman. 